5 Shaw SE, Binns SH, Birtles RJ, Day MJ, Smithson R, Kenny MJ. Molecular evidence of tick-transmitted infections in dogs and cats in the United Kingdom. Vet Rec 2005; 157: 645-648.

SK Mishra', S Murjaneh', MS Morgan², PR Simcock ${ }^{1}$ and S Glover 3,1

${ }^{1}$ West of England Eye Unit, Royal Devon and Exeter Hospital (Wonford), Exeter, UK

${ }^{2}$ Microbiology Department, Royal Devon and Exeter Healthcare, NHS Foundation Trust, Havitree, Exeter, UK

${ }^{3}$ Anatomy Department, College of Medicine, Blantyre, Malawi

Correspondence: PR Simcock, West of England

Eye Unit, Royal Devon and Exeter Hospital

(Wonford), Barrack Road, Exeter EX2 5DW, UK

Tel: +44139240 6008;

Fax: + 441392406022

E-mail: psimcock@hotmail.com

Eye (2007) 21, 850-851; doi:10.1038/sj.eye.6702705; published online 19 January 2007

Sir,

\section{Intraocular pressure measurement and goldmann calibration. An eye opening review of practice in United Kingdom}

The accurate measurement of intraocular pressure (IOP) is necessary for management of glaucoma and other ocular diseases. Recent studies have reinforced the importance of raised IOP as the main risk factor for the progression of glaucoma. ${ }^{1-4}$ Several methods are employed in clinical practice for measuring IOP, however Goldmann applanation tonometry is the most reliable and accurate method in clinical practice. The tonometer must be correctly calibrated to ensure accurate IOP measurement. There is little data available regarding the recommended frequency of Goldmann calibration.

Suggestions by several independent authors range from checking calibration before every session ${ }^{5}$ to an arbitrary annual or bi-annual check. ${ }^{6}$

In order to address this matter we sent out postal questionnaires to all 905 ophthalmology consultants registered with the Royal College of Ophthalmologists (RCO) in the UK. We enquired about the current method employed for measuring IOP and investigated the current and ideal practice for checking Goldmann calibration and the individual(s) responsible for this task.
Our survey had a response rate of $45.6 \%$ (413 out of 905). Goldmann tonometry was reported to be used by $99 \%$, hand held contact tonometry (perkins and tonopen) by $55.7 \%$ and non-contact methods by $3.1 \%$ of the responders. Trans-tarsal tonometry (TDGc-01 tonometer) was used by $0.5 \%$ of the responders only in cases where other methods were impossible (eg paediatric cases or corneal pathology). Goldmann tonometry was reported to be used as the sole method for measuring IOP by $58.2 \%(240 / 413)$ of the responders and $41.8 \%(173 / 413)$ stated they used multiple techniques already mentioned.

Personnel involved in measuring IOP included doctors, nursing staff and health care assistants. Goldmann tonometry was used by all the doctors, two-thirds of the nursing staff and half of the health care assistants (HCA's). Handheld tonometry was more popular amongst HCA's (88\%) and nursing staff (58.3\%) in comparison to doctors $(18 \%)$.

According to the consultants, the individuals responsible for checking Goldmann calibration were mainly doctors $(47.2 \%)$. Nearly a third $(29.7 \%)$ of the responsible individuals were service engineers and a fifth $(18.8 \%)$ allied health care professionals (nurses, orthoptists and HCA's). However one-fifth (19.3\%) of the responders were unaware who was responsible.

When asked, who should shoulder the responsibility for Goldmann calibration ideally, almost half (47.5\%) of the responders felt that doctors should but more responders felt other health care professionals could be involved.

(Allied health care professionals (36.8\%), service engineers $(39.9 \%)$ and $1.2 \%$ had no opinion).

The manufacturer of the most commonly used Goldmann tonometer (Haag-Streit, Switzerland) ${ }^{7}$ recommends that Goldmann calibration checks to be performed before every clinic. The most popular routines for the current frequency of checking Goldmann calibration (Appendix 1) were annually $(18.6 \%)$, one monthly $(17.4 \%)$ and weekly (13.8\%). Only in $6.1 \%$ of responders stated that the calibration was checked before every clinic. But significantly $39.3 \%$ (356 out of 905) of the consultants stated that calibration was not routinely checked.

Regarding the ideal routine for checking Goldmann calibration, most favoured either a weekly (30.3\%) or 3 monthly (24.9\%) routine. Only $11.4 \%$ felt it should be checked before very clinic while $2.2 \%$ thought it should only be checked in the event of an abnormal reading and $1.5 \%$ had no opinion about it.

Several factors play an important role to explain the disparity between manufacturer's recommendation and the current or even ideal practice for Goldmann calibration checks. These include the pressures of time in busy clinics, missing calibration bars, unawareness to the need of checking calibration frequently and inability to carry out Goldmann calibration. 
Although the response rate to our survey was rather low at $45.6 \%$ nonetheless we have demonstrated that from over 400 responders, about $20 \%$ did not know who was responsible for Goldmann calibration and up to $40 \%$ stated calibration was not routinely checked.

Furthermore $58 \%$ of the consultants felt that Goldmann tonometer calibration checks should be done more often with more involvement of other health care professionals.

We recommend that a responsible individual(s) to be designated to ensure the accuracy of Goldmann tonometer in clinics. The frequency of Goldmann calibration checks should be adhered to as closely as possible to manufactures recommended guidelines depending on the local resources.

\section{References}

1 Kass M, Heuer D, Higginbotham E, Johnson C, Keltner J, Miller J et al. The Ocular Hypertension Treatment Study:
A randomised trial determines that topical ocular hypotensive medication delays or prevents the onset of primary openangle glaucoma. Arch Ophthalmol 2002; 120: 701-713.

2 Gordon M, Beiser S, Brandt J, Heuer D, Higginbotham E, Johnson C et al. The Ocular Hypertension Treatment Study: Baseline factors that predict the onset of primary open-angle glaucoma. Arch Ophthalmol 2002; 120: 714-720.

3 Collaborative Normal-Tension Glaucoma Study Group. The effectiveness of intraocular pressure reduction in the treatment of normal-tension glaucoma. Am J Ophthalmol 1998; 126: 498-505.

4 The Agis Investigators. The Advanced Glaucoma Intervention Study (AGIS): The relationship between control of intraocular pressure and visual field deterioration. Am J Ophthalmol 2000; 130: 429-440.

5 Sandhu S, Chattopadhyay S, Kevin M, Ray-Chaudhuri N et al. Frequency of Goldmann Applanation Tonometer Calibration Error Checks. J Glaucoma 2005; 14: 215-218.

6 Whitacre M, Stein R. Sources of error with use of GoldmannType Tonometers. Surv Ophthalmol 1993; 38: 1-30.

7 Haag-Streit. Goldmann Applanation Tonometer Instruction Manual. 2003 Available at:www.haag-streit.com. Accessed on 12 November 2005.

\section{Appendix 1}

\section{Intraocular pressure measurement and calibration national survey}

Thank you for sparing the time to participate in this questionnaire.

All entries are anonymous.

We would encourage you to answer as honestly as possible (you can choose more than two options where appropriate).

\begin{tabular}{|l|l|l|l|l|}
\hline Question 1 & \multicolumn{3}{|l|}{ Who usually measures the intraocular pressure and what method(s) are employed? } \\
\hline & Goldmann & Tonopen & Trans Tarsal & Non Contact \\
\hline Consultant & & & & \\
\hline Registrar & & & & \\
\hline Senior House Officer & & & & \\
\hline Other e.g. Staff Grade & & & & \\
\hline Nurse & & & & \\
\hline Health Care Assistant & & & \\
\hline
\end{tabular}

Question $2 \quad$ How often is the calibration checked on your Goldmann tonometer?

Before every clinic

Every day

Once a week

Once a month

Once a year

Not routinely

Other: 


\begin{tabular}{|c|c|}
\hline Question 3 & Who checks the calibration? \\
\hline$\square \quad$ Servicing Engineer & \\
\hline$\square \quad$ Orthoptist & \\
\hline$\square \quad$ Nurse & \\
\hline$\square \quad$ Senior House Officer & \\
\hline$\square \quad$ Registrar/Staff Grade & \\
\hline$\square \quad$ Consultant & \\
\hline$\square \quad$ Other:....... & \\
\hline
\end{tabular}

\begin{tabular}{|l} 
Question 4 \\
$\begin{array}{l}\text { What are your opinions regarding how often the Goldmann calibration should } \\
\text { be checked? }\end{array}$
\end{tabular}

Only after an abnormal result

Before every clinic

Daily

At least once a week

At least once every 3 months

At least once every 6 months

At least annually.

Other:

\section{Question 5}

Who should check the Goldmann calibration?

\begin{tabular}{|c|c|}
\hline$\square$ & Servicing Engineer \\
\hline$\square$ & Health Care Assistant \\
\hline$\square$ & Nurse \\
\hline$\square$ & Orthoptist \\
\hline$\square$ & The attending doctor \\
\hline$\square$ & Other:..... \\
\hline
\end{tabular}

Thank you for your time and patience!!

$\mathrm{J} \mathrm{Ng}^{1}$, S Kashani ${ }^{1}, \mathrm{~K}$ Qureshi ${ }^{2}$ and V Ferguson ${ }^{1}$

${ }^{1}$ Charing Cross Hospital, London, UK

${ }^{2}$ Moorfields Eye Hospital NHS Trust, London, UK

Correspondence: S Kashani MRCP, MRCOphth, Whipps Cross Hospital, Whipps Cross road E11

1NR, London

Tel: + 02085395522;

Fax: 02085588155.

E-mail: shahdoc@hotmail.com

All Authors confirm that this original material has not been published previously in any journals. There are no issues to declare with regards to ethical adherence, competing interests or financial interests.

Eye (2007) 21, 851-853; doi:10.1038/sj.eye.6702706; published online 2 February 2007
Sir,

Circumferential epithelial defect at flap margins in patient with adenoviral conjunctivitis and previous LASIK

Laser in situ keratomileusis (LASIK) is an increasingly popular procedure for the treatment of myopia, astigmatism, and hyperopia. With time, the corneal flap created will adhere to the posterior stromal bed but the interface and flap remain at risk of complications, including diffuse lamellar keratitis (DLK) and traumatic dislocation, for many years following the procedure. ${ }^{1-3}$ We describe a patient who presented with viral conjunctivitis and a large epithelial defect at the flap margins 2 years following uncomplicated LASIK.

\section{Case report}

A 34-year-old man presented with a 1 week history of redness and watering of both eyes, associated with discomfort and blurred vision. The symptoms had initially started in the right eye and then spread to the left within days. He had undergone uncomplicated LASIK 